Société d'histoire de la révolution de 1848 et des

révolutions du XIXe siècle

$53 \mid 2016$

Mobilités, savoir-faire et innovations

\title{
Brésil : les 200 ans de la « Mission française » et l'œuvre de Jean-Baptiste Debret
}

\section{Isabel Lustosa}

Traducteur : Traduit du portugais (Brésil) par Myriam Bennaroch

\section{OpenEdition}

\section{Journals}

Édition électronique

URL : http://journals.openedition.org/rh19/5114

DOI : $10.4000 /$ rh19.5114

ISSN : $1777-5329$

Éditeur

La Société de 1848

Édition imprimée

Date de publication : 1 décembre 2016

Pagination : 146-152

ISSN : 1265-1354

Référence électronique

Isabel Lustosa, "Brésil : les 200 ans de la " Mission française » et l'œuvre de Jean-Baptiste Debret », Revue d'histoire du XIXe siècle [En ligne], 53 | 2016, mis en ligne le 21 décembre 2017, consulté le 03 janvier 2020. URL : http://journals.openedition.org/rh19/5114; DOI : 10.4000/rh19.5114 


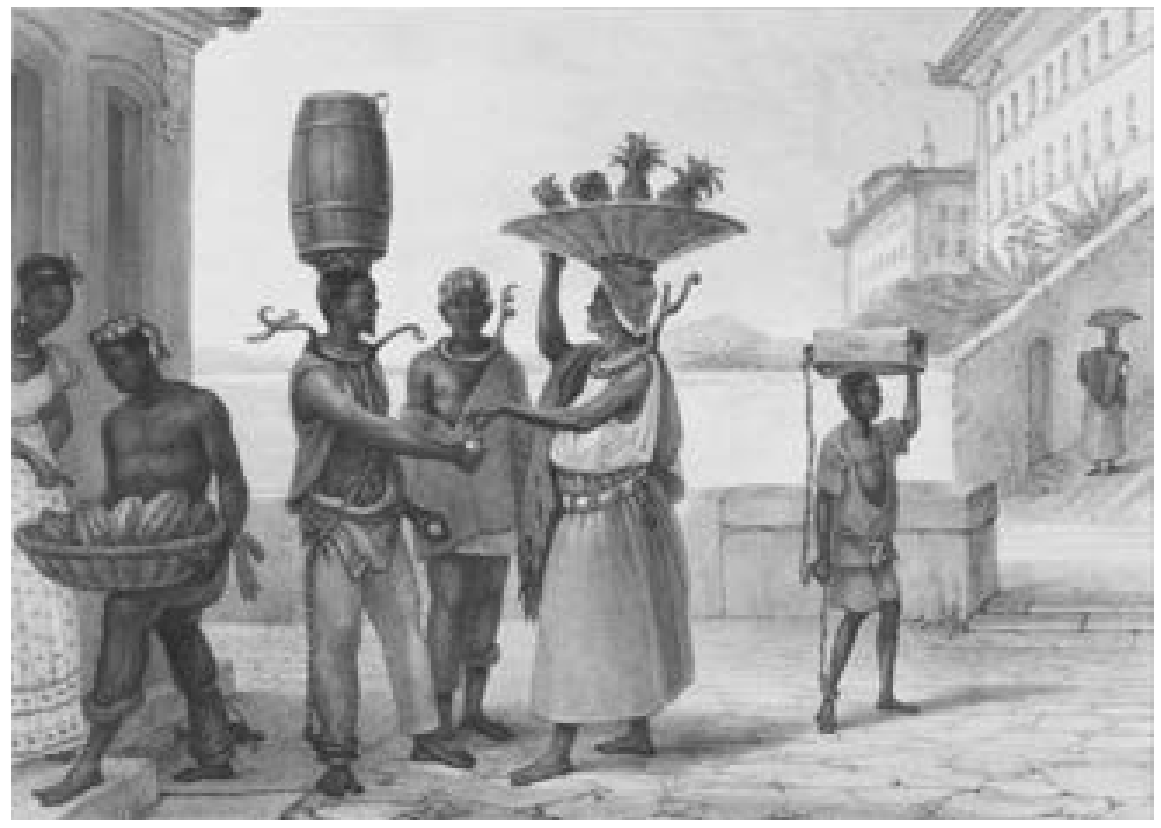

Illustration I : «Le collier de fer. Châtiment des fugitifs». Les "esclaves de gain» parcouraient les rues pour vendre des biens et des services, puis versaient leurs gains à leur propriétaire en fin de journée. La scène les montre portant des chaînes et des colliers de fer, ce qui indique qu'ils essayaient eux aussi de s'échapper, même s'ils étaient quelque peu rétribués pour leur travail et qu'ils jouissaient d'une relative liberté par rapport à ceux qui travaillaient sur les plantations de sucre ou dans le service domestique (Jean-Baptiste Debret, Voyage pittoresque et historique au Brésil, Paris, Firmin Didot, tome II, 1835, planche 42).

\section{Isabel Lustosa : Brésil : les 200 ans de la "Mission française» et l'œuvre de Jean-Baptiste Debret}

La polémique autour de la célèbre Mission française, déclenchée quelques années après le débarquement des artistes qui la composaient, demeure d'actualité. Le 26 mars 1816, le navire américain Calphe accosta à Rio de Janeiro. À bord, se trouvait un groupe de 40 personnes qui avaient embarqué au Havre - des artistes et des artisans, accompagnés de leur famille et de leur personnel. Comme Joachim Lebreton, le chef de l'expédition qui venait d'être démis de son poste à l'Institut de France, les artistes arrivés à Rio avaient connu un vif succès à l'apogée du Consulat de Bonaparte. Après la Restauration, dépouillés de leur prestige et de leur emploi, ils se cherchèrent un avenir dans d'autres pays.

Au Brésil, le groupe s'établit sous le patronage de la couronne portugaise. Il avait pour but d'implanter une Académie des arts qui ne verra le jour que dix ans plus tard. L'arrivée de ce groupe, qui fut alors connu sous le nom de "colonie Lebreton", avant de prendre plus tard le nom de Mission française, 


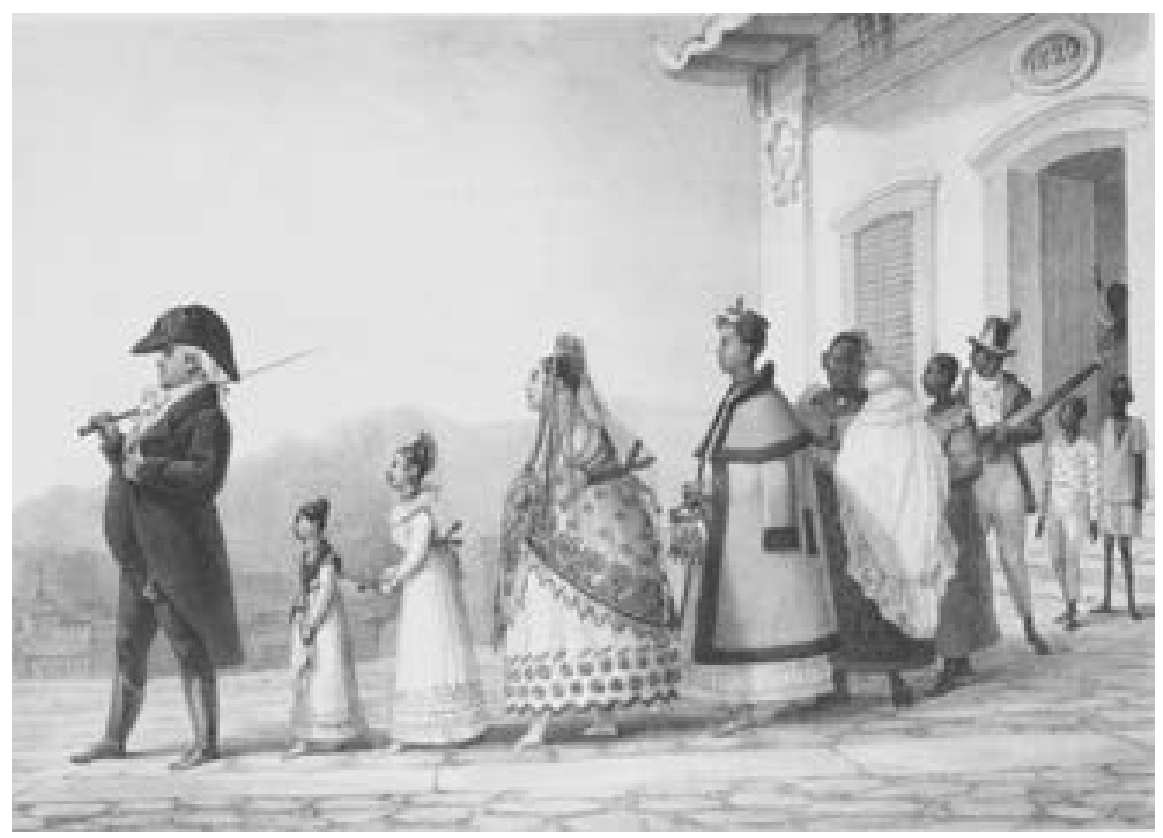

Illustration II : «Un employé de gouvernement sortant de chez lui avec sa famille». Debret représente cette famille moyennement fortunée partant à la promenade en bon ordre : le chef de famille est suivi de ses enfants classés par âge, de la mère enceinte, de sa femme de chambre (une esclave métisse), de la nourrice (une esclave noire) et de l'esclave de la nourrice; vient ensuite le domestique noir du maitre; un jeune esclave qui se forme au service; puis l'esclave de tous les autres, récemment acheté; le gardien de la maison est le cuisinier (Debret, Voyage pittoresque..., planche V).

suivit de peu le rétablissement des relations diplomatiques avec la France et s'inscrivit dans un mouvement massif d'entrée de Français, commerçants pour l'essentiel, mais aussi artistes, scientifiques, éditeurs, couturiers, chapeliers, parfumeurs et coiffeurs, qui contribuèrent de manière décisive à l'évolution des normes culturelles relatives aux arts plastiques, au théâtre, à la musique, à la littérature, à la mode et aux mœurs tout au long du XIX ${ }^{\mathrm{e}}$ siècle et dans les premières décennies du XX $\mathrm{XX}^{\mathrm{e}}$ siècle.

L'expédition se distinguait toutefois des autres flux migratoires par certaines particularités. A partir des années 1820, une polémique née dans la presse, opposait les artistes français et un artiste portugais qui posa la question de savoir si ces artistes français étaient venus au Brésil à l'invitation du roi Jean VI, ou si cette expédition n'avait été que l'action collective d'artistes désœuvrés se proposant de "construire l'Amérique». Les analyses récentes des documents concernant les négociations préparatoires à cette expédition ont établi définitivement le caractère extra-officiel du voyage. Ils sont encore l'objet d'études visant à identifier les différentes visions du Brésil à l'origine des projets de Lebreton et de son groupe. 
C'est dans cette perspective que se situent les travaux d'Elaine Dias sur les relations entre Lebreton et Alexander von Humboldt, qui a inspiré l'expédition au Brésil ${ }^{14}$. Les recherches de Dias apportent du nouveau sur des questions déjà abordées dans les travaux de Lilia Schwarcz sur Nicolas Antoine Tauney. Schwarcz remarque l'ambivalence de la couronne portugaise : si elle était intéressée par ces artistes qui, forts de leur expérience au service de Napoléon, contribueraient à forger une image civilisée de la Cour de Rio de Janeiro, son enthousiasme envers leur passé bonapartiste ne pouvait que rester nuancé. D'où, conclut l'historienne, l'ambiguïté de la correspondance entre les diplomates portugais et Lebreton en $1815^{15}$.

La bibliographie sur la Mission française s'est enrichie ces dernières années de nouveaux travaux universitaires portant plus particulièrement sur les ouvrages de Nicolas Taunay, Grandjean de Montigny et Jean-Baptiste Debret. Jean-Baptiste Debret (1768-1848) a été le plus étudié des trois, car c'est le seul à avoir publié un récit de son expérience dans les tropiques. Son Voyage pittoresque et historique au Brésil est paru en France chez Firmin Didot Frères en trois volumes, les deux premiers en 1834 et 1835 , et le troisième en 1839. Le livre, qui n'a été que récemment réédité en France - en 2014, par l'Imprimerie Nationale, sous la direction de Jacques Leenhardt - a été accueilli avec une quasi-indifférence en Europe et a fait l'objet de commentaires négatifs au Brésil, en raison notamment des représentations de la société brésilienne véhiculées dans le second volume considérées comme blessantes.

Les membres de l'Institut historique et géographique brésilien (IHGB), une institution créée en 1838 et qui célébrait l'action civilisatrice des Européens au sein de la jeune nation brésilienne, n'ont pas apprécié de découvrir un Rio de Janeiro où les esclaves parcouraient les rues alourdis de chaînes, d'entraves au cou et de masques en fer, où ils étaient flagellés en public, ni d'avoir à se reconnaître dans les images d'une élite indolente, aux mœurs peu élégantes, qui se confondait dans son intimité avec ses propres esclaves. Jacques Leenhardt s'est penché sur les avis rendus en 1840 par la commission de l'IHGB sur les gravures de Debret. Il a tenté de savoir comment cette entité, qui cherchait à établir les éléments constitutifs de la nationalité en excluant toute référence à l'esclavage, a disqualifié le travail de l'artiste français ${ }^{16}$.

Recouverte d'une chape de silence pendant près d'un siècle, l'œuvre de Debret fut réhabilitée dans le contexte du Modernisme brésilien des années 1920. Anderson Trevisan analyse les corrélations entre le contenu de cette

14. Elaine Dias, «Le Breton entre Humboldt e Bachelier : referências para o ensino artístico brasileiro ", Arte e suas Instituiçôes : Anais do XXXIII, Colóquio do Comitê Brasileiro de História da Arte, Rio de Janeiro, 2013, volume 1, p. 415-428.

15. Lilia Moritz Schwarcz, O sol do Brasil, São Paulo, Cia das Letras, 2008.

16. Jacques Leenhardt, "Jean-Baptiste Debret : um olhar francês sobre os primórdios do império brasileiro", Sociologia \& Antropologia, Rio de Janeiro, novembre 2013, p. 509-523. 
œuvre et le moment où la sociologie brésilienne entreprend une révision des théories raciales qui prédominaient jusque-là, en particulier à partir de la publication en 1936 de Casa Grande e Senzala de Gilberto Freyre, qui aurait ouvert la porte à la publication, en 1940, de la première édition en portugais du livre de Debret ${ }^{17}$.

Valeria Lima pointe du doigt la prétention historiographique de Debret et affirme qu'il aurait eu l'intention de montrer un Brésil qui, à partir de l'arrivée de la cour en 1808 «se civilisait». D'où son effort pour présenter, dans le troisième volume, des aspects de la vie royale, des cérémonies publiques et de l'action des autorités ${ }^{18}$. Tous ces auteurs reconnaissent toutefois que c'est le caractère d'ethnographe avant la lettre de Debret, perceptible dans ses nombreuses scènes représentant le quotidien de Rio de Janeiro, où il vécut, qui a fait de son œuvre l'une des sources historiques et iconographiques les plus importantes pour l'étude du Brésil du début du XIX siècle.

Isabel Lustosa est chercheuse à la fondation Casa de Rui Barbosa, Rio de Janeiro

Traduit du portugais (Brésil) par Myriam Bennaroch

17. Anderson Trevisan, «Arte, memória e sociedade : Jean-Baptiste Debret e sua (re) descoberta na primeira metade do século XX no Brasil», RESGATE, volume XX, $\mathrm{n}^{\circ} 23$, janvier-juin 2012, p. 18-27.

18. Valéria Alves Esteves Lima, J.-B. Debret, historiador e pintor : 1816-1839, Campinas, São Paulo, Unicamp, 2007. 